\title{
The American Society for Radiation Oncology's 2015 Core Physics Curriculum for Radiation Oncology Residents
}

\author{
Jay Burmeister, PhD, ${ }^{*}$ Zhe Chen, PhD, ${ }^{\dagger}$ Indrin J. Chetty, PhD, \\ Sonja Dieterich, $\mathrm{PhD}, \S$ Anthony Doemer, MS, \\ Michael M. Dominello, D0,* Rebecca M. Howell, PhD, \\ Patrick McDermott, PhD, Adrian Nalichowski, MS," \\ Joann Prisciandaro, PhD, ** Tim Ritter, PhD, ${ }^{\dagger \dagger}$ Chadd Smith, PhD, \\ Eric Schreiber, PhD, Timothy Shafman, MD, ${ }^{\ddagger}$ Steven Sutlief, PhD, \\ and Ying Xiao, PhD
}

*Department of Oncology, Karmanos Cancer Center/Wayne State University, Detroit, Michigan; ${ }^{\dagger}$ Department of Therapeutic Radiology, Yale University, New Haven, Connecticut; ${ }^{\ddagger}$ Department of Radiation Oncology, Henry Ford Hospital, Detroit, Michigan; ${ }^{\S}$ Department of Radiation Oncology, University of California - Davis, Sacramento, California; "Department of Radiation Physics, The University of Texas MD Anderson Cancer Center, Houston, Texas; "Department of Radiation Oncology, Beaumont Health, Royal Oak, Michigan; ${ }^{\#}$ Karmanos Cancer Center, Detroit, Michigan; **Department of Radiation Oncology, University of Michigan, Ann Arbor, Michigan; ${ }^{\dagger \dagger}$ VA Ann Arbor Healthcare and the University of Michigan, Ann Arbor, Michigan; ${ }^{\ddagger \dagger}$ Department of Radiation Oncology, University of North Carolina, Chapel Hill, North Carolina; ${ }^{\S} 21$ st Century Oncology, Fort Myers, Florida;

"II Department of Radiation Oncology, University of California - San Diego, La Jolla, California; and

"Tepartment of Radiation Oncology, Thomas Jefferson University, Philadelphia, Pennsylvania

Received Nov 20, 2015, and in revised form Feb 10, 2016. Accepted for publication Mar 11, 2016.

\section{Summary}

The American Society for Radiation Oncology Physics Core Curriculum Subcommittee has updated the recommended physics curriculum for radiation
Purpose: The American Society for Radiation Oncology (ASTRO) Physics Core Curriculum Subcommittee (PCCSC) has updated the recommended physics curriculum for radiation oncology resident education to improve consistency in teaching, intensity, and subject matter.

Methods and Materials: The ASTRO PCCSC is composed of physicists and physicians involved in radiation oncology residency education. The PCCSC updated existing sections within the curriculum, created new sections, and attempted to provide
Reprint requests to: Jay Burmeister, $\mathrm{PhD}$, Wayne State University School of Medicine, Karmanos Cancer Center, Detroit, MI 48201. Tel:

313-576-9617; E-mail: burmeist@karmanos.org

Conflict of interest: none.

Supplementary material for this article can be found at www.redjournal.org.
Acknowledgments - The authors thank Dr Geoffrey Ibbott for his thorough review and valuable feedback, Dr Prajnan Das and Ahmad Hammoud for their review and contributions to the components of the curriculum, and the members of the Board of Directors of the American Society for Radiation Oncology (ASTRO) for their review and constructive comments. 
oncology resident education in an effort to identify the most important physics topics for preparing residents for careers in radiation oncology, to reflect changes in technology and practice since the publication of previous recommended curricula, and to provide practical training modules in clinical radiation oncology physics and treatment planning. additional clinical context to the curricular material through creation of practical clinical experiences. Finally, we reviewed the American Board of Radiology (ABR) blueprint of examination topics for correlation with this curriculum.

Results: The new curriculum represents 56 hours of resident physics didactic education, including a 4-hour initial orientation. The committee recommends completion of this curriculum at least twice to assure both timely presentation of material and reemphasis after clinical experience. In addition, practical clinical physics and treatment planning modules were created as a supplement to the didactic training. Major changes to the curriculum include addition of Fundamental Physics, Stereotactic Radiosurgery/ Stereotactic Body Radiation Therapy, and Safety and Incidents sections, and elimination of the Radiopharmaceutical Physics and Dosimetry and Hyperthermia sections. Simulation and Treatment Verification and optional Research and Development in Radiation Oncology sections were also added. A feedback loop was established with the $\mathrm{ABR}$ to help assure that the physics component of the ABR radiation oncology initial certification examination remains consistent with this curriculum.

Conclusions: The ASTRO physics core curriculum for radiation oncology residents has been updated in an effort to identify the most important physics topics for preparing residents for careers in radiation oncology, to reflect changes in technology and practice since the publication of previous recommended curricula, and to provide practical training modules in clinical radiation oncology physics and treatment planning. The PCCSC is committed to keeping the curriculum current and consistent with the ABR examination blueprint. (C) 2016 The Authors. Published by Elsevier Inc. This is an open access article under the CC BY-NC-ND license (http://creativecommons. org/licenses/by-nc-nd/4.0/).

\section{Introduction}

In 2002, an ad hoc Committee on Physics Teaching to Medical Residents was organized by the Radiation Physics Committee of the American Society for Radiation Oncology (ASTRO). The ad hoc committee's main objective was to develop a core curriculum for physics teaching within radiation oncology residency programs to improve consistency in radiation oncology physics teaching, intensity, and subject matter. The outcome of this effort was the first ASTRO radiation oncology resident physics core curriculum, which was published in 2004 (1). The second goal of the ad hoc committee was to assure periodic review and revision of the curriculum, and this resulted in 2 subsequent published core curricula $(2,3)$.

In 2009, ASTRO created the Physics Core Curriculum Subcommittee (PCCSC) with the mission of "making recommendations for physics curriculum based on resident career needs, communicate with the American Board of Radiology (ABR) so that they may use these recommendations to update examinations, and move to centralized web-based teaching aids." The 2015 curriculum represents the efforts of this subcommittee to meet the first 2 of these 3 aims and becomes the fourth in a series of core physics curricula for radiation oncology residents. This curriculum includes updates to the specification, content, and organization of the subjects. In addition, detailed appendices that include specific topics and references have been completely revised.
A significant effort was made to incorporate modern technology and techniques while still preserving the most important fundamental physics components of the curriculum. Although technology changes rapidly, fundamental physics does not, and a foundation in basic physical principles will prepare the resident to understand new technology. Indeed, the primary objective of physics training for radiation oncology residents is to produce better practitioners by providing a solid understanding of the physical principles and technical details involved in the process of radiation therapy. This understanding is more useful than is the mere memorization of information in confronting a previously unencountered problem. Educators of radiation oncology residents bear the difficult responsibility of imparting both of these important aspects: providing the relevant technical information and cultivating critical thinking skills.

The role of physics and biology education in preparing medical residents for future scientific research and innovation in our profession should not be underestimated. We currently enjoy an abundance of outstanding medical school graduates interested in entering the radiation oncology profession, many of them with a strong background in technology, physical science, or both. Indeed, in 2014, more applicants with $\mathrm{PhDs}$ in addition to their medical degrees were matched to residencies in radiation oncology than in any other specialty (4). Teaching residents both the basic science and technical details supporting the biology and physics of radiation therapy helps the residents to become better clinicians and to ask the right questions 
that can lead to scientific inquiry. As leaders in our profession have previously asserted, it is critical that we adequately prepare the next generation of clinician scientists if we are to contribute substantially to the future of cancer research and innovation $(5,6)$. The more we help residents understand how the fundamentals of medical physics pertain to the current state of radiation oncology, the more likely they are to find ways to improve upon it.

Within the context described above, the purpose of this article is to describe the process of revising the ASTRO physics curriculum for radiation oncology residents and to present the resulting recommended curriculum.

\section{Methods and Materials}

The PCCSC is composed of physicists and physicians from various academic institutions with radiation oncology residency education programs. Members of the committee also have associations with the American Association of Physicists in Medicine (AAPM), the American College of Radiology (ACR), the ABR, or more than one of these organizations. In preparation for the review of the curriculum by the PCCSC, a questionnaire was developed and sent to all committee members requesting data on the suitability of existing subjects, the potential modification or elimination of current subjects, the addition of new subjects to the ASTRO core curriculum, and the existence of practical clinical training components in the physics curriculum at their institutions. Because curricular recommendations do not always match current practice, the survey asked committee members not only how many hours they spent on each topic in their own institution's curricula but also how many hours they thought were necessary to adequately cover the topic. Once the updated subject list was determined, the members of the PCCSC reviewed and created the outline and references for each section. Finally, a set of practical, hands-on radiation oncology clinical physics and treatment planning modules were created as supplements to the didactic training material.

The ASTRO PCCSC is committed to assuring that this proposed curriculum remains relevant until the next published curriculum and that it provides an effective study framework for residents preparing for the physics board examination. The ABR produces a blueprint of physics topics from which questions for the physics component of the ABR initial certification (IC) examination are drawn and which is also provided to candidates as a study guide (7). We have established an annual feedback loop with the ABR to assure both that this curriculum remains consistent with the ABR blueprint and that we consider feedback from examinees who have taken the physics component of the ABR IC examination. The ABR blueprint was updated in 2015, and this feedback process included the independent review of the ASTRO curriculum and the ABR blueprint by both the PCCSC and an ABR trustee for assurance of correlation. Because the content for the
Radiation Oncology In-Training (TXIT) examination is based on this ABR study guide, we expect continued consistency between the TXIT examination and this curriculum (8).

\section{Results}

The revised curriculum represents 56 hours of resident physics didactic education, including a 4-hour initial orientation. Specific topics are listed in Table 1, along with the recommended hours for the curriculum, suggested references, and associated section(s) of the ABR blueprint. Details for each of these curricular topics are provided in Appendix E1. The references listed in Table 1 represent chapters from general reference texts on radiation oncology. Although this results in the most concise list of recommended reference texts, it does not include important references that specifically cover only particular topics. However, complete lists of specific references for each chapter of the curriculum are listed in Appendix E2 (available online at www.redjournal.org). The total recommended curriculum has been reduced by 4 hours from the 2010 curriculum. In addition to this core curriculum, practical clinical physics modules and treatment planning modules are also included and are recommended as a supplement to the didactic training material. Table 2 provides the module titles for these practical components. Major changes to the curriculum structure include the addition of a fundamental physics section, the removal of stereotactic radiosurgery and stereotactic body radiation therapy from the Special Procedures section and the creation of an independent 2-hour section for both topics, the removal of the Hyperthermia section, and the de-emphasis of the Radiopharmaceutical Physics and Dosimetry topic from its own section to a subsection of the Special Procedures section. Also, minor changes and additions to existing sections are included, such as the addition of a subsection on Volumetric Arc Therapy, a Simulation and Treatment Verification section, and an optional Research and Development in Radiation Oncology section. Finally, the Radiation Incidents and Bioterrorism Response Training section was changed to Safety and Incidents. Appendix E1 provides the recommended details of the curriculum, Appendix E2 provides recommended references for teaching material, Appendix E3 provides a glossary of acronyms, Appendix E4 provides a set of practical clinical radiation oncology physics modules, and Appendix E5 provides a set of practical modules for radiation therapy treatment planning (all appendices are available online at www.redjournal.org).

On the survey, the number of actual and recommended hours for each subject typically deviated only where newer procedures or technology required expanded content within the curriculum or where older procedures were being phased out. The number of recommended hours for each subject was also fairly consistent among respondents, and an average value for each topic served as the starting point for 
Table 1 Recommended topics, hours of instruction, suggested general reference chapters, and corresponding 2015 ABR blueprint sections for the American Society for Radiation Oncology's 2015 core physics curriculum for radiation oncology residents

\begin{tabular}{|c|c|c|c|c|}
\hline Chapter & Title & Hours & General references & Correlated ABR sections \\
\hline 0 & Orientation & 4 & & None \\
\hline 1 & Fundamental physics & 1 & PMD:2; EP:1; RS:1 & I.1, III.1-2 \\
\hline 2 & Atomic and nuclear structure & 2 & WH:1; FK:1,2; PMD:3; EP:1; RS:2 & I. $2-4$, II.1-5 \\
\hline 3 & Production of kilovoltage $\mathrm{x}$-ray beams & 2 & WH:2; PMD:4-5; EP:5; FK:3; RS:1 & III.3, IV.4, VII.1, 2 \\
\hline 4 & $\begin{array}{l}\text { Production of megavoltage x-ray } \\
\text { beams }\end{array}$ & $3^{*}$ & $\begin{array}{l}\text { WH:4; PMD:9; PM:1; EP:5; FK:4; } \\
\text { RS:8,9; JVD1:10,11 }\end{array}$ & IV.1,3 \\
\hline 5 & Radiation interactions & 3 & $\begin{array}{l}\text { WH:2,3,16; PMD:6; PM:2; EP:1,6; } \\
\text { FK:5; RS:4 }\end{array}$ & III.4, V.1-6, VII.1 \\
\hline 6 & Radiation quantities and units & 1 & $\begin{array}{l}\text { WH:5; PMD:7; PM:3; EP:2,6; FK:8; } \\
\text { RS:6 }\end{array}$ & VI.1-3 \\
\hline 7 & Radiation measurement and calibration & $3 *$ & $\begin{array}{l}\text { SD:1,2; WH:5,6; PMD:8,11; PM:3; } \\
\text { EP:2,3,9; FK:6,8; RS:5; JVD1:19; } \\
\text { JVD2:9 }\end{array}$ & VI.4-9 \\
\hline 8 & $\begin{array}{l}\text { Photon beam characteristics and } \\
\text { dosimetry }\end{array}$ & $7^{*}$ & $\begin{array}{l}\text { SD:2; WH:7,8,11; PMD:10,12-14; } \\
\text { PM:4-7; EP:6,7; FK:7,9-11; } \\
\text { RS:10,11 }\end{array}$ & XII.1,4, VIII, IX \\
\hline 9 & $\begin{array}{l}\text { Electron beam characteristics and } \\
\text { dosimetry }\end{array}$ & $2^{*}$ & $\begin{array}{l}\text { SD:15; WH:11; PMD:15; EP:8; } \\
\text { FK:14; RS:12 }\end{array}$ & X.1-11 \\
\hline 10 & Imaging fundamentals & 4 & $\begin{array}{l}\text { WH:9: PMD:19; PM:5; EP:7,15; } \\
\text { FK:12; JVD1:7; JVD2:2,7 }\end{array}$ & $\mathrm{XI}$ \\
\hline 11 & Simulation and treatment verification & $2^{*}$ & $\begin{array}{l}\text { SD:3,6,7,13,18,19; WH:9,11; } \\
\text { PMD:19; PM:5; EP:7,15; } \\
\text { FK:8,12,26; RS:13; JVD1:3-6; } \\
\text { JVD3:7-8 }\end{array}$ & XII.3, XIV \\
\hline 12 & Informatics & 1 & SD:11; WH:10; JVD1:14 & XVII \\
\hline 13 & Intensity modulated radiation therapy & $3^{*}$ & $\begin{array}{l}\text { SD:16; WH:11; PMD:20; EP:15; } \\
\text { FK:20; RS:14; JVD1:12,15; JVD2:4 }\end{array}$ & XIII \\
\hline 14 & $\begin{array}{l}\text { Prescribing, reporting, and evaluating } \\
\text { radiation therapy treatment plans }\end{array}$ & 1 & $\begin{array}{l}\text { SD:14; WH:11; PMD:14; PM:8; EP:7; } \\
\text { FK:11,19; JVD2:5 }\end{array}$ & XII. 2,5 \\
\hline 15 & Special procedures & 2 & $\begin{array}{l}\text { SD:23/24; PM:5; EP:15; FK:14,18; } \\
\text { JVD1:17; JVD2:10 }\end{array}$ & X.12, XII.7, XV.8 \\
\hline 16 & Brachytherapy & $6^{*}$ & $\begin{array}{l}\text { SD:8,20-22; WH:12,13; PMD:16; } \\
\text { EP:13; FK:15,23-25; RS:15; } \\
\text { JVD118 }\end{array}$ & II.4, XV.1-7,9-10, XVI.3-4 \\
\hline 17 & Quality assurance & $2^{*}$ & $\begin{array}{l}\text { SD:4,5; WH:15; PMD:18; EP:11,12; } \\
\text { FK:17; RS:8 }\end{array}$ & XX.4, IV.5 \\
\hline 18 & Radiation protection and shielding & $2^{*}$ & $\begin{array}{l}\text { SD:10; WH:14; PMD:17; EP:5,16; } \\
\text { FK:16; RS:16 }\end{array}$ & VI.3, XVI.1-2,5-6 \\
\hline 19 & Safety and incidents & 1 & SD:12; PMD:18; EP:12; JVD3:12 & $\mathrm{XX} .2$ \\
\hline 20 & Particle therapy & 2 & $\begin{array}{l}\text { SD:9; WH:16; PMD:20; EP:5; FK:27; } \\
\text { JVD1:20,21 }\end{array}$ & IV.2, XVIII \\
\hline 21 & $\begin{array}{l}\text { Stereotactic radiosurgery/stereotactic } \\
\text { body radiation therapy }\end{array}$ & 2 & $\begin{array}{l}\text { WH:15; SD:17; PMD:20; EP:15; } \\
\text { FK:21,22; JVD1:16; JVD3:5 }\end{array}$ & XII.6 \\
\hline 22 & $\begin{array}{l}\text { Research and development in } \\
\text { Radiation Oncology Physics } \\
\text { (Optional) }\end{array}$ & $1^{\dagger}$ & & None \\
\hline
\end{tabular}

General reference abbreviations: EP = Podgorsak EB. Radiation Oncology Physics: A Handbook for Teachers and Students. Vienna: International Atomic Energy Agency; 2005. FK = Khan FM, Gibbons JP. The Physics of Radiation Therapy. Philadelphia: Lippincott Williams \& Wilkins; 2014. JVD1 = Van Dyk J. The Modern Technology of Radiation Oncology. Volume 1. Madison, WI: Medical Physics Publishing; 1999. JVD2 = Van Dyk J. The Modern Technology of Radiation Oncology. Volume 2. Madison, WI: Medical Physics Publishing; 2005. JVD3 = Van Dyk J. The Modern Technology of Radiation Oncology. Volume 3. Madison, WI: Medical Physics Publishing; 2013. PM = Metcalfe P, Kron T, Hoban P. Physics of Radiotherapy X-Rays and Electrons. 2nd ed. Madison, WI: Medical Physics Publishing; 2007. PMD = McDermott, P, Orton, C. The Physics and Technology of Radiation Therapy. Madison, WI: Medical Physics Publishing; 2010. RS = Stanton R, Stinson D. Applied Physics for Radiation Oncology. Revised ed. Madison, WI: Medical Physics Publishing; 2009. SD = Dieterich S, Ford E, Pavord D, et al. Practical Radiation Oncology Physics. Philadelphia: Elsevier; 2015. WH = Hendee WR, Ibbott GS, Hendee EG. Radiation Therapy Physics. Hoboken, NJ: Wiley-Liss; 2005.

See Appendix E2 for complete references for each section.

* Indicates subject matter that should be complemented with a physics clinical/laboratory rotation.

$\dagger$ Optional section. 
Table 2 Recommended practical clinical radiation oncology physics and treatment planning supplements to the American Society for Radiation Oncology's 2015 core physics curriculum for radiation oncology residents

\begin{tabular}{ll}
\hline $\begin{array}{c}\text { Practical } \\
\text { component }\end{array}$ & \multicolumn{1}{c}{ Modules } \\
\hline $\begin{array}{l}\text { Clinical radiation } \\
\text { oncology } \\
\text { physics }\end{array}$ & $\begin{array}{c}\text { 1. Introductory laboratory/linac } \\
\text { primer }\end{array}$ \\
& $\begin{array}{l}\text { 2. External beam therapy with } \\
\text { photons and electrons: absolute } \\
\text { dosimetry for machine calibration }\end{array}$ \\
& $\begin{array}{l}\text { 3. External beam therapy with } \\
\text { photons and electrons: relative } \\
\text { dosimetry for beam model } \\
\text { characterization }\end{array}$ \\
& 4. External beam therapy with \\
& photons and electrons: in vivo \\
& dosimetry and delivery \\
& verification \\
& 5. Brachytherapy \\
6. Radiation protection and \\
shielding
\end{tabular}

committee discussion to determine the final recommended number of hours for each topic. The total didactic curriculum hours among respondents ranged from 40 to 70 hours with a mean (standard deviation) of 52.5 (8.8) hours, which agrees fairly well with the final recommendation of 56 hours. The final recommendation represents the total number of hours for all sections in Table 1, not including the final optional section. As such, this recommendation is based on an estimate by the committee of the number of hours required to cover all elements of the detailed outline of each section provided in Appendix E1.

The survey responses also showed that the number of times residents were required to complete this curriculum varied among institutions, but it was common for residents to complete the curriculum more than once. Four of 8 respondents required residents to take the full curriculum twice, two required it 3 times, and the remaining two either gave residents the option to take it a second time or required residents to do so if their TXIT scores were below a specified cutoff. The committee recommends that residents complete this curriculum at least twice during their residency education. This recommendation is based primarily on the following challenge. Although residents need to be exposed to physics concepts very early in the residency program to gain general familiarity with the scientific and technical processes involved, residents in these early stages may be ill equipped to appreciate the details of the radiation oncology physics didactic education and clinical training. Covering the material again later in the program allows the resident to more fully grasp the nuances of this training once the resident has a more extensive context within which to place it.

Seven of 8 committee members responding to the survey reported that their institutions had a laboratory or clinical rotation component; however, the total reported hours within this component varied from 4 to 60 , with a mean of 12 hours. In addition, the laboratory component was not mandatory at 4 of these institutions, and these laboratory components varied significantly in content. Written descriptions of these rotations included the following components: clinical dosimetry (treatment planning), treatment calculations, linear accelerator design and function, radiation detectors, treatment unit calibration, observation of quality assurance for special procedures, safety/emergency training, and involvement in or observation of quality assurance tests and other physics activities.

The PCCSC recommends that the radiation oncology residency physics education curriculum contain a laboratory/clinical component that supplements the didactic material presented in the courses. A set of example laboratory exercises is provided in Appendix E4 as a guideline for developing practical experiences to help residents solidify didactic concepts. Ideally, each module of the practical clinical radiation oncology physics component will be performed after completion of the associated didactic material. The PCCSC also recommends a radiation therapy treatment planning component, and a comprehensive set of treatment planning modules is provided in Appendix E5 as a template for such a component. We anticipate that the practical treatment planning component will be completed either during a designated treatment planning rotation within the residency curriculum or gradually throughout the residency program and integrated with the disease-site specific clinical rotations. Whereas Appendix E5 provides only a set of recommended treatment sites and teaching points, examples of detailed treatment planning exercises exist elsewhere, for example by Golden et al (9).

Resident feedback from the medical physics component of the ABR IC examination is collected by survey after the examination and will be reviewed annually by the chair of the ABR Radiation Oncology Physics Examination Committee and the chair of the ASTRO PCCSC. This review will help shape future curricula by providing insight into the examinees' perceptions of their relative level of preparation for various topics and their core skills and familiarity with particular procedures and technologies. The first review was completed in October 2015. The most common request from examinees was a desire for increased clinical applicability of examination material. We hope that the revisions within this curriculum and the addition of practical, hands-on clinical components will help improve the link between didactic material and practical application both in education programs and in examination content. 


\section{Discussion}

The updated curriculum was completed and approved by the ASTRO Board of Directors in October 2015. Technology and techniques in radiation oncology change very rapidly; therefore, it is important that this curriculum be updated regularly and that individual residency programs perform annual reviews and continuous quality improvement. Such annual program reviews should consider the content, philosophy, and goals of resident physics education and include suitable participation from all stakeholders. In addition, every attempt should be made to incorporate physics principles into clinical rotations to assure that the relationship between the didactic material and its clinical application is clear.

The updated curriculum presented here can be used as a guide to the development of didactic radiation oncology resident physics education and to practical, hands-on experiences in the application of the didactic concepts. We anticipate that the addition of these practical experiences will not only improve understanding of core concepts and their clinical applications but also offer educators a platform to re-evaluate current teaching practices in an effort to enhance the resident education process. It is our hope that by supplementing lectures with other educational experiences, residents will gain reinforced understanding and improved retention of the material in this curriculum. Although we make no effort in this document to address "how" to teach, many valuable resources are available to educators. Several relevant examples are provided by the AAPM Medical Physicists as Educators (10). Instead of restating this pedagogic information, our goal here is to provide a clear and concise framework of "what" to teach.

Although the ABR blueprint provides a list of topics for study, the list provided in Appendix E1 of this curriculum is much more detailed, and we hope that it will serve as a reference to both instructors and residents. This comprehensive list covers all topics that the committee believes are important for a practicing radiation oncologist, and it may also provide guidance to the authors of the ABR, TXIT, and Raphex examinations. We anticipate continued interaction between the PCCSC and the ABR in maintaining independent but consistent curricula. Although we have not made a specific recommendation for any individual textbook for the didactic course, we have identified several general radiation oncology physics reference texts useful for educating radiation oncology residents and specific references for each section of the curriculum.

\section{Conclusions}

The ASTRO physics core curriculum has been updated by the ASTRO PCCSC to identify the most important physics topics for preparing residents for a career in radiation oncology and to reflect changes in technology and practice since the publication of previous recommended curricula. We anticipate that physics educators will use this curriculum to structure or modify their resident physics education courses and that the ABR, TXIT, and Raphex examinations will remain consistent with this curriculum. A feedback loop has been established to assure that the blueprint used to create the physics component of the ABR IC examination will remain consistent with the ASTRO physics core curriculum and that both the ABR and ASTRO PCCSC will review and consider residents' post examination feedback during future updates of the curriculum. We also invite resident physics instructors to contribute to the continued development of this curriculum by emailing feedback to research@astro.org. The curriculum will be updated again in 3 years, and we anticipate the development of centralized web-based teaching aids that will supplement this curriculum to further improve the quality and standardization of physics education for radiation oncology residents.

\section{References}

1. Klein EE, Balter JM, Chaney EL, et al. ASTRO's core physics curriculum for radiation oncology residents. Int J Radiat Oncol Biol Phys 2004;60:697-705.

2. Klein EE, Gerbi BJ, Price RA Jr., et al. ASTRO's 2007 core physics curriculum for radiation oncology residents. Int J Radiat Oncol Biol Phys 2007;68:1276-1288.

3. Xiao Y, De Amorim Bernstein K, Chetty I, et al. The American Society for Radiation Oncology's 2010 core physics curriculum for radiation oncology residents. Int J Radiat Oncol Biol Phys 2011;81: 1190-1192.

4. National Resident Matching Program: Charting Outcomes in the Match. Available at: www.nrmp.org/wp-content/uploads/2014/09 /Charting-Outcomes-2014-Final.pdf. Accessed April 7, 2016.

5. Vapiwala N, Moghanaki D, Movsas B. Cultivating tomorrow's clinician scientists: We reap what we sow. Int J Radiat Oncol Biol Phys 2015;92:206-210.

6. Formenti SC, Bonner JF, Hahn SM, et al. Raising the next generation of physician-scientists: The chairs' perspective. Int J Radiat Oncol Biol Phys 2015;92:211-213.

7. The American Board of Radiology: Radiation Oncology Initial Certification Study Guide for Radiation Oncology Physics. Available at: http:// www.theabr.org/sites/all/themes/abr-media/pdf/ic-ro-study-phys.pdf. Accessed April 7, 2016.

8. Hatch SS, Vapiwala N, Rosenthal SA, et al. Radiation oncology resident in-training examination. Int J Radiat Oncol Biol Phys 2015; 92:532-535.

9. Golden D, Stepaniak C, Chmura S. Radiation Oncology Self-Directed Dosimetry Workshops: AP/PA Spine, 3-Field Breast, and IMRT. MedEdPORTAL Publications; 2012. Available at: https://www .mededportal.org/publication/9297. Accessed April 7, 2016.

10. American Association of Physicists in Medicine: Medical Physicists as Educators Subcommittee Educator Resources. Available at: wikifull.aapm.org/index.php/MPESC. Accessed April 7, 2016. 